\title{
ALTERAÇÕES DA PREVIDÊNCIA SOCIAL BRASILEIRA APÓS A CONSTITUIÇÃO FEDERAL DE 1988 SOB A ÓTICA DO WELFARE STATE
}

\author{
BARRETO, Maiara Couto ${ }^{1}$ \\ TEIXEIRA, Elaine Aparecida ${ }^{1}$ \\ SILVA, Raquel Andrade e ${ }^{1}$ \\ COSTA, Thiago de Melo teixeira da ${ }^{1}$
}

RESUMO: O objetivo deste trabalho foi analisar as principais alterações legais ocorridas na Previdência Social brasileira após a Constituição Federal de 1988, utilizando-se como base os modelos de Welfare State estabelecidos por Esping-Andersen. Foi necessário compreender o histórico das Políticas Públicas de Previdência Social e o papel do Estado, e os Modelos de Estado de Bem-Estar Social. Trata-se de uma análise de conteúdo aplicado aos modelos de Wefare State Liberal, Conservador e Social-democrata. Concluiu-se que as reformas brasileiras posteriores à instituição da Constituição Federal de 1988 possuem características principalmente dos regimes Conservador e Liberal.

Palavras-chave: Welfare State. Previdência Social. Reforma.

\section{ALTERATIONS IN THE BRAZILIAN SOCIAL SECURITY AFTER THE FEDERAL CONSTITUTION OF 1988 UNDER WELFARE STATE}

SUMMARY: The aim of this work was to analyze the main legal changes occurred in Brazilian Social Security after the Federal Constitution of 1988, using as basis the Welfare State models established by Esping-Andersen. It was necessary to understand the history of the Public Policies of Social Security and the role of the State, and the Models of the Social Welfare State. This is a content analysis applied to Welfare State Liberal, Conservative and Social Democrat models. It was concluded that the Brazilian reforms subsequent the institution the Federal Constitution of 1988 have characteristics mainly of the Conservative and Liberal regimes.

Keywords: Welfare State. Social Security. Reform.

\section{INTRODUÇÃO}

Até meados do século XVII, a proteção social era feita normalmente através das famílias, vizinhos e instituições religiosas. Somente com a segunda Revolução Industrial, no final do século XIX, de acordo com Horvath (2006), que as nações começaram a desenvolver a proteção aos trabalhadores, que gradativamente, foi estendendo aos demais indivíduos da sociedade. Posteriormente, os colapsos econômicos, políticos e sociais advindos da primeira guerra mundial impulsionaram a criação das primeiras políticas públicas de proteção social ou seguridade social no mundo (HOBSBAWM, 2006).

Em decorrência das crises econômicas e efeitos das guerras mundiais houve a intensificação das políticas de proteção social, com a expansão do Estado de Bem-Estar social-Welfare State (WS) que se configura, na visão de Viana (1998), como sendo a absorção pelo Estado da obrigação de fornecimento de serviços à sociedade, como forma de suprir as necessidades básicas dos cidadãos, através das políticas de proteção social.

\footnotetext{
${ }^{1}$ Universidade Federal de Viçosa
} 
Para Esping-Andersen (1991), o WS vai além de garantir o bem-estar básico, envolve cidadania, cobertura universal e garantia de oportunidades iguais para todos. Ainda de acordo com esse autor, existem tipologias diferentes de WS que vão desde a total dependência do indivíduo ao mercado, havendo assim, mínima participação do Estado até a um sistema de ampla proteção e cobertura universal, propiciando a desmercadorização do indivíduo. Essas tipologias são classificadas como Welfare State Liberal, Conservador e Social-democrata.

No Brasil, a ampliação das políticas de seguro social, foi decorrente da expansão do poder funcional da Previdência Social de controlar os conflitos sociais. Os enfoques previdenciários anteriores aos anos 1920 tiveram um âmbito estreito como alguns projetos de leis e poucos alcançaram implementação completa. Portanto vários estudos consideram a Lei Eloy Chaves de 1923, como marco inicial do sistema previdenciário brasileiro. Esse decreto determinava a criação da caixa de aposentadorias e pensões (CAP's) para os trabalhadores das estradas de ferro existentes no país (SANTOS, 2009).

Muitas transformações legislativas ocorreram ao longo dos anos. Contudo, com a promulgação da Constituição Federal de 1988 - CF/88, o sistema de proteção social no Brasil passou por uma significativa alteração. Foi com a CF/88 que se instituiu a definição 'Seguridade Social', inclusive tratando-a como abrangente e universal. A proteção foi estendida a todos os integrantes da sociedade. Assim todos os brasileiros passaram a ter o direito à saúde, à cobertura previdenciária e à assistência social. Trouxe a concepção de que o Estado deve atender a quem precisa e não apenas quem contribui. Dessa forma o Brasil deixou de ser um Estado Providência, que garante a proteção apenas aos trabalhadores, para ser um Estado de Seguridade Social, que garante proteção universal à população. Este sistema está fundamentado no conceito de que a seguridade social deve garantir o mínimo social necessário à existência humana digna (HOBSBAWM, 1995; HORVATH, 2006; MENEZES, 2013).

A CF/88 trouxe aspectos inovadores no âmbito da previdência social, como por exemplo a instituição do piso salarial para todos os beneficiários, inclusive aposentado rural, criação de planos de benefícios (unificados para trabalhadores rurais e urbanos), dentre outros benefícios. Com a CF/88 exaltou-se um estado democrático de direito. Todavia, após a instauração da Carta Magna, surgem algumas reformas de cunho majoritariamente restritivos.

Com base nessas considerações iniciais, o presente artigo busca responder a seguinte questão: quais os modelos de Welfare State mais se assemelham às alterações legais da previdência social após a Constituição Federal de 1988?

Para tanto esta pesquisa tem como objetivo analisar as principais alterações legais acerca da Previdência Social após a CF/88 com base nas tipologias de Welfare State Liberal, Conservador e Socialdemocrata, estabelecidas por Esping-Andersen.

O foco da análise será os seguintes documentos legislativos: Lei no 8540/1992 que dispõe sobre a contribuição do empregador rural; Emenda Constitucional no 20/1998 que institui o fator previdenciário e o critério de tempo de contribuição; Emenda Constitucional no 41/2003 dispõe sobre a reformulação dos critérios de aposentadoria dos servidores públicos; e a Lei $\mathrm{n}^{\circ} 13.183 / 2015$ que cria a regra de aposentadoria por tempo de contribuição 85/95.

$\mathrm{O}$ artigo possui como hipótese que as alterações legais da previdência social ocorridas após a CF/88 têm viés predominantemente econômico com foco na financeirização do Estado, ocorrendo um distanciamento dos aspectos de proteção social. A contribuição do mesmo se insere no quadro dos trabalhos que buscam aprofundar o debate sobre as reformas previdenciárias ocorridas no Brasil, trazendo a discussão para o âmbito da administração pública, e buscando refletir sobre os avanços e limites dessa área, com vistas a contribuir também para o campo científico. 


\section{A PREVIDÊNCIA SOCIAL BRASILEIRA E O PAPEL DO ESTADO}

Zelar por seus cidadãos é uma obrigação do Estado Social, sendo por meio das políticas públicas que essa função é executada, com o intuito de promover o bem-estar da coletividade (Guimarães, 2006). É importante perceber que muitas pessoas ainda dependem do Estado, sendo necessária sua intervenção para auxiliar na sobrevivência destes cidadãos. O Estado intervém quando da identificação de uma questão relevante para aquela sociedade que, sozinha, não o resolveria ou levaria tempo elevado e prejudicial para a parcela da população afetada. Uma das questões identificadas como necessária a atuação estatal diz respeito à proteção do cidadão quando está impossibilitado de trabalhar.

Sendo assim, a Previdência Social tem como objetivo amparar o trabalhador das adversidades que poderiam afastá-lo do trabalho e gerar desenvolvimento socioeconômico no país, ainda mais considerando os benefícios em geral, por representarem grande relevância na estabilidade social do Brasil. Assim sendo, a interferência do Estado na economia através de políticas públicas e programas fundamenta-se pela busca de equidade e eficiência propositando indicadores sociais mais relevantes e consequentemente refletindo pelo melhor nível de bem-estar e de renda (CAVALIERI; PAZELLO, 2005).

A previdência social surgiu pelos embates por melhores condições de trabalho, os quais resultaram em diferentes sistemas protetivos, de acordo com as situações de cada país envolvido (IBRAHIM, 2011). No Brasil, a previdência social teve seu marco inicial em 1923 com aprovação da primeira legislação de Previdência Social que criou a caixa de pensões e aposentadoria para os empregados ferroviários (Decreto-Lei $\mathrm{n}^{\mathrm{o}}$ 4.682, de 24 de janeiro de 1923) conhecida como Lei Eloy Chaves, adotando-se o princípio de repartição simples e o conceito do welfare state (GURGEL, 2007). Com essa lei emergiram as bases legais e a percepção do uso da previdência como forma de lidar com a questão social, considera-a como ponto de partida do sistema previdenciário brasileiro.

Durante o século XX, o Brasil se constituiu em uma economia moderna com base industrial e urbana baseando em exportações de bens primários, modernizando e estendendo as regulações do Estado, assim como os mecanismos para as suas intervenções. Neste cenário, a evolução do sistema de proteção social dava ênfase às relações entre o capital e o trabalho, com reduzida atenção aos direitos sociais e à cidadania. Foi entre 1930 e 1970 que as políticas sociais receberam pequenas características que permitem defini-las como um Estado de bem-estar social (DRAIBE, 1993).

A República que se inicia em 1930 com o golpe liderado por Getúlio Vargas introduz uma extensa pauta de direitos sociais, atendendo os pontos principais da lista de reivindicações do movimento operário, expandindo e modificando o padrão de proteção social. O país começa a conhecer então, políticas sociais nacionais (KERSTENETZKY, 2012). A década de 1930 inaugura mudanças significativas na história do país, contudo ao longo dos anos, alterações importantes ocorrem e subsidiam a estrutura da proteção social brasileira, no entanto, o seu caráter não redistributivo permanecia. Houve um crescimento e modernização do país no período de regime militar, porém as desigualdades sociais aumentavam. Surgem muitos questionamentos e disputas em torno do welfare state quando o país inicia sua transição democrática na década de 80, aumentando a participação política, sendo um dos pontos em questão torná-lo mais inclusivo e universal (GUERREIRO, 2010; KERSTENETZKY, 2012).

Em 1988 instaurou-se a Constituição Federal Brasileira, em um cenário de entraves e tentativas de se manter o conservadorismo em diversos pontos, ainda existia o agravante de uma crise econômica interna, altas taxas de inflação que repercutiam negativamente na pobreza e na desigualdade. O contexto internacional também não era favorável, pois vivia-se um momento de hegemonia do conservadorismo, acompanhando orientações do liberalismo, que pregava o Estado mínimo e, por conseguinte a desconstrução de um sistema amplo de proteção social (BRASIL, 1994 ; GUERREIRO, 2010). Houve 
muitos avanços, elaborou-se a Constituição mais democrática já existente no Brasil. Ela consagrou um novo patamar para os direitos de cidadania brasileira, expandindo os políticos, resguardando os civis e incorporando os sociais (GUERREIRO, 2010).

Com o implemento da CF/88 em seu art. 194, adotou-se a expressão "Seguridade Social" estabelecendo um sistema de proteção social amplo, universal e solidário, buscando assegurar saúde, previdência e assistência para todos os cidadãos brasileiros (GOMES, 2011, p. 35). A necessidade de assegurar os bens materiais essenciais para o futuro dos indivíduos é a gênese da previdência social.

Ainda merecem ser ressaltados alguns direitos incorporados na $\mathrm{CF} / 88$, como aumento da licença maternidade de 90 dias para 120 dias e da licença paternidade de 1 dia para 5 dias; a estipulação do salário mínimo nacional e a vinculação deste valor como o piso para os benefícios da previdência e da assistência social; aumento da vinculação para a educação de $13 \%$ para $18 \%$ das receitas tributárias da União e manteve em 25\% a vinculação dos estados e municípios; a incorporação, como direito, do Benefício de Prestação Continuada - BPC, uma renda mínima de sobrevivência para os idosos ou deficientes, em situação de pobreza e sem capacidade laboral; além de aprofundar o processo de descentralização, gerando maior autonomia para Estados e municípios (BRASIL, 1988 ; GUERREIRO, 2010).

Isto posto, esta nova lógica de uma rede de proteção social integrada e universalista, presente na $\mathrm{CF} / 88$, torna indivíduos mais pariformes tanto pela questão de dignidade social quanto pela maior igualdade de oportunidades, fundamental para que haja diminuição da desigualdade social. Em suma, as alterações culminadas com a Carta Magna iniciam um novo sistema de proteção social pautado na concepção de Seguridade Social que universaliza os direitos sociais incluindo a saúde, a assistência social e a previdência como questão pública, de responsabilidade do Estado.

Entretanto, as políticas sociais no Brasil, estiveram muito dependentes de projetos de desenvolvimento econômico de diferentes regimes políticos, deixando a um plano secundário a adesão de estratégias para melhoria efetiva das condições de vida e criação de padrões mínimos de igualdade social. Sabe-se que o padrão predominante foi o da cidadania regulada, onde o acesso a direitos dependia da inserção no mercado formal de trabalho, com privilégio aos setores urbanos e indispensáveis ao processo de industrialização. Outro ponto importante do desenvolvimento das políticas sociais e que não pode ser desconsiderado é o caráter antidemocrático. No período de 1923 a 1985, as políticas sociais se desenvolveram mais em período autoritários, deixando um legado de alta centralização, baixa interferência da população e pouca transparência. Embora já exista um longo período democrático desde o fim do regime militar, essas características ainda permeiam as estruturas setoriais da política social (LOBATO, 2016).

A ordem social instituída na Carta Magna, estreou um modelo avançado de estado de bem-estar comparado com o que existia na época, exercendo importante impacto nas condições de vida da população. Contudo, elementos estruturais à sustentação desse modelo, receberam alterações ao longo do tempo de caráter distinto da Constituição Federal de 1988. Ao longo da sua trajetória a previdência social brasileira sofreu significativas alterações, as quais refletiram mudanças significativas para a sociedade. $\mathrm{O}$ conhecimento das reformas previdenciárias ocorridas após a CF 88 contribui para o entendimento da previdência brasileira atualmente.

\section{OS MODELOS DE ESTADO DE BEM-ESTAR SOCIAL}

A definição de Estado de Bem-Estar Social ou Welfare State é fundamental para o entendimento deste trabalho. Wilensky (1975) define que Welfare State é uma proteção oferecida pelo governo na forma de padrões mínimos de renda, alimentação, saúde, alojamento e instrução, todos garantidos pelo 
Estado e assegurado a qualquer cidadão como um direito político e não como caridade.

Já Briggs (2006), afirma que Welfare State é um Estado no qual se usa deliberadamente o poder organizado em um esforço para alterar as forças do mercado em no mínimo três direções, são elas: garantir aos indivíduos e as famílias uma renda mínima, independentemente do valor de mercado de seu trabalho ou de sua propriedade; reduzir a exposição à insegurança, colocando os indivíduos e famílias em posições de enfrentar contingências sociais; e assegurar que a todos os cidadãos sejam oferecidos os mais altos padrões de um conjunto reconhecido de serviços sociais.

Dessa forma, tem-se que a seguridade social se origina das várias lutas em busca de melhores condições de trabalho, as quais sucederam em diferentes sistemas protetivos em conformidade com os contextos de cada país. Os pressupostos históricos que permitiram a formação teórica plena do Welfare State se iniciam com os modelos bismarkiano e beveridgeano (IBRAHIM, 2011).

O modelo Bismarkiano surgiu na Alemanha pelo chanceler Otto Von Bismarck com o nítido caráter político, mas foi marcado pelo início dos movimentos sociais com o objetivo de tentar diminuir a pobreza. Esse modelo foi proveniente das greves e pressões dos trabalhadores relatando a necessidade social de se estabelecer métodos de proteção contra os riscos ao ser humano. Suas características assemelham-se as de seguros privados: os benefícios cobrem principalmente os trabalhadores, é condicionado a contribuição, e o montante das prestações é proporcional a contribuição efetuada (ESPING-ANDERSEN, 1990 ; HOBSBAWM, 1995).

Em outro contexto econômico e político, durante a Segunda Guerra Mundial, é formulado na Inglaterra o Plano Beveridge, no qual aponta críticas ao modelo Bismarckiano e apresenta a instituição do Welfare State, que insere a lógica da cidadania. Sugere ao Estado a sua intervenção para a garantia de condição de cidadão, neste sistema os direitos têm caráter universal. Enquanto Bismarck tinha uma visão individual da sociedade, Beveridge pensava não apenas nos trabalhadores, mas em toda a população (ESPING-ANDERSEN, 1990, HOBSBAWM, 1995 ; BOSCHETTI, 2000). Foram as divergências desses sistemas que provocaram o aparecimento de outros modelos de seguridade social no mundo, respeitando as demandas culturais e as classes sociais existentes em cada país.

No período entre guerras o Estado de Bem-Estar ganhou expressão, contexto em que o capitalismo passou por grandes crises e mudanças. O que tornou a situação ainda mais crítica foi o elevado desemprego e a estagnação econômica dos países europeus (HOBSBAWN, 2006). Para Vianna (1998) o avanço do capitalismo fez com que o Estado reduzisse sua atuação social aos que mais necessitavam, tornando-se uma preocupação crescente quanto aos novos rumos do Welfare State, um desafio para o pensamento tradicional sobre política social. As resultantes provenientes da economia aberta com redução da autonomia dos países na formulação de políticas econômicas e a adequação às normas do sistema internacional competitivo ocasionaram baixo crescimento econômico.

Dessa forma, o avanço do Wefare State como uma atuação do Estado assistencial que garante padrões mínimos de seguridade social aos cidadãos, passa a ser estudado por diferentes perspectivas, levando cada país a criar suas estratégias de desenvolvimento, pois não há formatos homogêneos de Welfare State.

Para melhor compreender os diferentes formatos de Welfare State, Esping Andersen (1991) desenvolve três tipologias diferentes. $O$ autor se baseia no grau de desmercadorização (ou desmercantilização) da política social, ou seja, a independência em relação ao mercado. Fundamentado no grau de desmercadorização são definidas distintas formas de relação entre Estado, mercado e família. Dessa forma o autor propõe três regimes de Welfare State, quais sejam: Modelo Liberal, Modelo Conservador e Modelo Social-Democrata. Os quais serão utilizados neste artigo, como categorias de análises para o estudo das alterações legais da previdência e sobretudo, são modelos considerados 
clássicos no debate do tema Welfare State.

Cabe destacar que, o grau de mercantilização do regime é o quanto a provisão de bem-estar é dependente do mercado. Logo, quanto mais o nível de bem-estar depender do mercado, mais há a mercadorização do regime. Já a desmercantilização refere-se à possibilidade de os indivíduos obterem um nível socialmente aceitável de vida independente da participação no mercado. Isso implica analisar as políticas sociais tendo como referência o grau de independência que essas políticas conseguem garantir aos indivíduos de sobreviverem para além das relações de mercado (ESPING-ANDERSEN, 1991; BENEVIDES, 2011 ).

Sendo assim, no Welfare State Liberal predominam os mecanismos de mercado e assistência aos comprovadamente pobres, com poucas transferências universais e com planos tímidos de previdência social (ESPING-ANDERSEN, 1991). São identificados como políticas residuais, responsabilidade financeira do benefício e peso do setor privado na provisão do bem-estar. O Estado encoraja o mercado subsidiando esquemas privados de previdência. A proteção social do Estado fica concentrada nos mais pobres, logo a classe média precisa buscar no mercado a provisão de bem-estar. Observa-se ainda nesse modelo a igualdade das necessidades mínimas, ou seja, os benefícios refletem o mínimo necessário à sobrevivência, de modo a não encorajar o distanciamento do mercado de trabalho. Ademais, há pouco gasto com políticas relacionadas à promoção do emprego (BENEVIDES, 2011). Dessa forma, os principais componentes desse modelo podem ser resumidos como sendo a desmercadorização mínima, o foco na lei do mercado e a participação mínima do Estado.

No modelo Welfare State Conservador ou corporativista, os indivíduos têm seus direitos sociais atendidos pelo Estado principalmente a partir de sua ocupação econômica. Esse regime defende que o Estado só deve intervir quando a família falha. Ele assume que para aqueles que estão fora do mercado de trabalho a família é a principal provedora de bem-estar. Os benefícios como aposentadoria, por exemplo, são nesse regime proporcionais à contribuição efetuada imediata com as necessidades do beneficiário. Há pouco desenvolvimento das políticas que ajudam a conciliar a maternidade e elevar a taxa de participação feminina no mercado. A seguridade social oferece extensos benefícios e uma cobertura ampla para a população empregada, porém os empregos têm altos custos. Nesse regime o mercado é marginal na geração do bem-estar e o papel central que ocupam as políticas previdenciárias são as políticas residuais voltadas para os segmentos de inclusão mais precários no mercado de trabalho, caracterizando-se por vincular a ação protetora do Estado ao pertencimento a determinados grupos (ESPING-ANDERSEN, 1991; BENEVIDES, 2011). Em síntese, para esse modelo o médio grau de desmercadorização, a participação marginal do Estado e o Estado subsidiário são os principais componentes a serem ressaltados.

O terceiro regime é o Social-democrata, o qual caracteriza o maior grau de desmercantilização. Esse modelo está pautado pelo grau de universalismo entre os benefícios, marcado por políticas universalistas, onde se busca garantir direitos idênticos. Todas as camadas da população são incorporadas ao sistema de proteção social com benefícios de acordo com os ganhos habituais e não residuais ou condicionados à contribuição prévia, como nos modelos liberal e conservador. Outra característica desse regime é de emancipar o indivíduo do mercado e retirar da família a responsabilidade de garantia do bemestar, ou seja, o Estado atua antes da família. Ocorrendo também a capacitação da independência individual, as garantias de renda universais, as políticas ativas de emprego e a extensa rede de segurança contra os riscos sociais (ESPING-ANDERSEN, 1991; BENEVIDES, 2011). Logo, pode-se sintetizar os principais componentes desse modelo como sendo a desmercadorização máxima, a emancipação do indivíduo do mercado e a participação central do Estado.

Dessa forma, essas são as características principais dos modelos de Welfare State apresentados na tipologia de Esping-Andersen (1991), das quais as análises das reformas previdenciárias após a CF/88 
foram pautadas.

\section{PROCEDIMENTOS METODOLÓGICOS}

Neste artigo utilizou-se a metodologia de pesquisa qualitativa com o emprego da técnica análise de conteúdo baseada na proposta de Laurence Bardin (2012). Observou-se os modelos de Welfare State que mais se assemelham às alterações legais da previdência social após a Constituição Federal de 1988.

\section{Análise de conteúdo}

A Análise de conteúdo é muito usada para descrever e interpretar o conteúdo de documentos e textos. Visa a revelar o que está escondido ou subentendido. Silva et al. (2005), definem a análise de conteúdo como um conjunto de procedimentos e técnicas que visam extrair sentidos dos textos por meio de unidades de análises, podendo ser palavras-chave, termos específicos, categorias ou temas, de maneira a permitir a identificar a frequência com que aparecem no texto, possibilitando fazer inferências replicáveis e válidas dos dados.

Bardin (2012) defende ainda que a análise de conteúdo deve ser organizada em torno de três polos cronológicos considerados básicos, são eles: i. pré-análise; ii. exploração do material e iii. tratamento dos resultados, inferência e interpretação.

A primeira fase refere-se à organização - leituras flutuantes, formulação de objetivos e indicadores. A segunda fase fica a cargo da elaboração do corpus, exaustão do material para reforçar as análises, definição das categorias e componentes; e a terceira fase é o momento de tornar os resultados brutos em significativos e válidos, concluir as análises agrupando as partes dos textos nas suas categorias ou classes objetivando responder a pergunta do estudo.

Por fim, optou-se por essa técnica para responder o problema de pesquisa por permitir a captação de resultados em tempo consideravelmente mais hábil que as demais técnicas. De acordo com Laville e Dionne (1999), uma operacionalização que facilite o trabalho do pesquisador é extremamente necessária.

\section{Roteiro para a análise de conteúdo}

Os procedimentos seguiram a seguinte cronologia:

- Formulação do corpus de análise com a seleção dos seguintes documentos legislativos: Lei ${ }^{\circ}$ 8540/1992; $\mathrm{EC} \mathrm{n}^{\circ}$ 20/1998; $\mathrm{EC} \mathrm{n}^{\circ}$ 41/2003; Lei n ${ }^{\circ} 13.183 / 2015$.

- Leitura exaustiva dos documentos afim de corroborar as categorias de análise e responder o objetivo desse estudo.

- Exploração das informações, elaboração das inferências e apresentação dos resultados.

Após a definição do corpus, houve a categorização e elaboração dos componentes específicos extraídos dos estudos de Esping-Andersen (1991), Draibe (1993) e Benevides (2011), apresentados na figura abaixo: 
Figura 1 - Categorias de análise e seus componentes

Lei 8540/1992- Dispõe sobre a contribuição do empregador rural.

EC 20/1998- Institui o fator previdenciário e o critério de tempo de contribuição. EC 41/2003- Reformula os critérios de aposentadorias dos servidores públicos.

Lei 13183/2015- Cria a regra 85/95 de aposentadoria por tempo de contribuição.

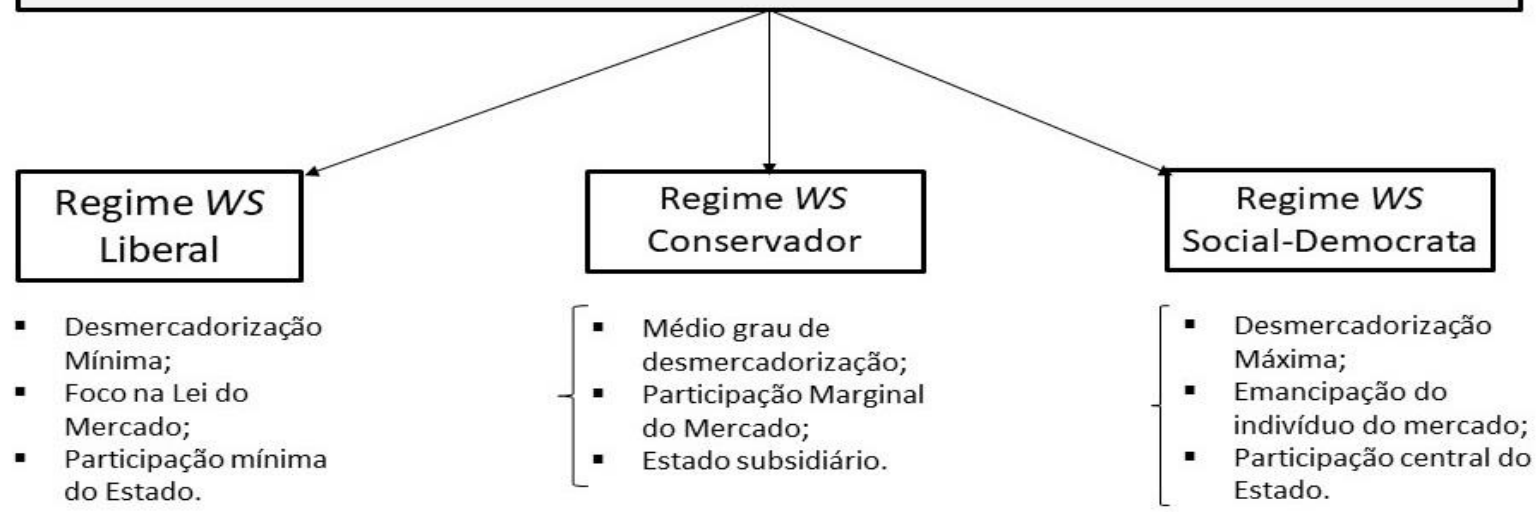

Fonte: Elaborado pelos autores com base em Esping-Andersen (1991).

Cada categoria definida possui seus componentes pautados no estudo de Esping-Andersen (1991) e foram apresentadas detalhadamente no referencial teórico. Finalizados tais procedimentos, a etapa seguinte consistiu no estudo das informações, associando-as às categorias de análise definidas.

\section{DISCUSSÃO E RESULTADO}

\section{Análise da Lei no 8540/1992}

A primeira análise referiu-se a Lei $n^{\circ} 8540 / 1992$ que instituiu a contribuição previdenciária do empregador rural para a seguridade social e alterou alguns dispositivos das Leis n/s 8.212/91 e 8.315/91.

No contexto anterior à $\mathrm{CF} / 88$ houve alguns pontos marcantes para o trabalhador rural, na década de 60, por exemplo, houve uma grande conquista que foi a criação do Estatuto do Trabalho Rural através da Lei $n^{\circ} 4.214 / 63$ que anos depois foi revogada pela Lei $n^{\circ} 5.889 / 73$. Entretanto foi com o Estatuto que se definiu pela primeira vez que os trabalhadores rurais passariam a ter acesso à previdência social através do Fundo de Assistência ao Trabalhador Rural. Antes da CF/88, os trabalhadores possuíam Regime Próprio de Previdência, conhecido como Prorural/Funrural - Programa de Assistência ao Trabalhador Rural. Com caráter assistencial, este programa assegurava benefícios no valor de meio salário mínimo, cujo acesso era restrito aos trabalhadores rurais que mantinham a condição de chefe de família. Por conseguinte, as mulheres e os jovens eram excluídos desse programa, exceto em relação à pensão por morte. Porém a média de idade no meio rural ficava abaixo dos 60 anos nas décadas de 60 e 70, fazendo com que poucos trabalhadores homens conseguissem ter acesso a tal benefício (HOVARTH, 2006).

Essa lei analisada foi promulgada no governo Itamar Franco, logo após o processo de Impeachment do presidente Fernando Collor de Melo. Diante desse cenário de incertezas, surge o Movimento Sindical dos Trabalhadores Rurais expressando a insatisfação com o modelo assistencial implantado visando a igualdade de direitos trabalhistas e previdenciários entre os trabalhadores rurais e urbanos. Contudo, foi com a CF/88 que os trabalhadores rurais foram incluídos no Regime Geral de Previdência Social-RGPS com direitos previdenciários, como: benefícios previdenciários no valor de um salário mínimo; aposentadoria por idade aos 60 anos para os homens e 55 para as mulheres; 
aposentadoria por invalidez; pensão por morte; salário-maternidade e auxílio-doença. O propósito do legislador constituinte era dar maior proteção ao grupo familiar.

A promulgação da $\mathrm{CF} / 88$ trouxe mudanças voltadas para a promoção do bem-estar em grupos que antes não eram atendidos sem que houvesse o aumento da receita previdenciária (Giambiagi ; Além, 2008). Dessa forma, os trabalhadores rurais viveram num cenário de grande resistência do governo, das quais o discurso dos ex-presidentes José Sarney, Fernando Collor e Fernando Henrique Cardoso - FHC era de que se os trabalhadores rurais passassem a integrar a previdência social, o Brasil iria tornar-se deficitário. Com a Lei no 8.540/1992, os direitos conquistados pela Constituição passaram a ser de caráter contributivos, sendo a contribuição da pessoa física do segurado especial no valor de $2,1 \%$ da receita bruta proveniente da comercialização da sua produção (BRASIL, 1992 ; HOVARTH, 2006).

Assim, apesar dessa lei ser pequena e trazer poucas, mas importantes alterações, observa-se que a referência crucial dela é a contribuição do empregador rural para a seguridade social. Dessa forma, o modelo conservador é o que mais se adequa em certos aspectos ao que foi realizado pela Lei ${ }^{\circ}$ 8540/92, visto que há exigências de contribuição do produtor rural, ressaltando características apenas de seguro social para grupos específicos e não de seguridade e universalismo, tornando o Estado apenas subsidiário. Quanto a desmercadorização, o produtor rural torna-se ainda mais dependente do mercado com as alterações trazidas nesta lei, que estão na contramão dos mecanismos institucionais para garantir provisão universal e gratuita. Haja vista que o sentido da desmercadorização é que todos os cidadãos possam ter acesso a bens e serviços, numa lógica de direito que torna irrelevante as diferenças econômicas e sociais do indivíduo.

\section{Análise da Emenda Constitucional nº 20/1998}

A EC n ${ }^{\circ}$ 20/1998 modificou o sistema previdenciário social e estabeleceu normas de transição, tais como: novas exigências para alcance de aposentadorias no RGPS; instauração de tempo mínimo de contribuição; mudança no cálculo do benefício de aposentadoria devido a institucionalização do fator previdenciário. Com essa emenda, deixou de existir a aposentadoria proporcional aos 25 anos de serviço, no caso de mulheres, e aos 30 anos de serviço, para homens, passando a exigir o mínimo de 30 e 35 anos de contribuição, respectivamente, como dispõe o art. 201, § $7^{\circ}$, do novo texto constitucional.

Considera-se o fator previdenciário como um aspecto importante que foi aprovado somente em 1999 pela Lei $\mathrm{n}^{\circ}$ 9.876, mas foi instrumento que operacionalizou as alterações trazidas pela emenda. Sua fórmula considera o tempo de contribuição, idade do trabalhador e expectativa de sobrevida. A sua finalidade é desestimular as aposentadorias precoces, pois assim os trabalhadores são estimulados a trabalharem mais, pois quanto maior o tempo de contribuição, maior o valor do benefício e quanto menor a idade no momento da aposentadoria, menor o valor do benefício. $\mathrm{O}$ fator previdenciário pode ser considerado como um caminho encontrado para a inserção de forma indireta na legislação da idade mínima para concessão de aposentadoria por tempo de contribuição. Isso causou impacto na população, pois culmina no atraso das concessões das aposentadorias e/ou estreita os valores dos benefícios.

Primeiramente, há fortes tendências dessa emenda ao modelo de Welfare State conservador por se tratar da aposentadoria por tempo de contribuição que é um benefício que está vinculado a uma ocupação econômica, destacando assim a segregação a um grupo específico.

A situação ocasionada pelo fator previdenciário de reduzir as aposentadorias ou prolongar o tempo de contribuição oferece margem para o indivíduo permanecer mais dependente do mercado. Por outro lado, caso o indivíduo venha a se aposentar com tempo mínimo de contribuição, terá seu benefício reduzido o que o tornará, mais uma vez, vulnerável ao mercado intervindo no seu bem-estar e qualidade 
de vida. Logo, a inserção do fator previdenciário traz tendências do modelo liberal haja vista que expressa fragmentos de preocupação com o equilíbrio financeiro e atuarial da previdência como apresentado no art. 40:

Art. 40 Aos servidores titulares de cargos efetivos da União, dos Estados, do Distrito Federal e dos Municípios, incluídas suas autarquias e fundações, é assegurado regime de previdência de caráter contributivo, observados critérios que preservem o equilíbrio financeiro e atuarial e o disposto neste artigo (Brasil, 1998, grifo nosso).

Dessa forma, nessa emenda sobressaem fortes tendências do Welfare State liberal que possui como característica políticas residuais e responsabilidade financeira do beneficiário. Vale considerar também o cenário da época, da qual FHC era o presidente e possuía diversas atitudes liberais, como as privatizações realizadas em seu mandato. De acordo com Abrúcio (2005), o tema central da agenda federativa do ex-presidente FHC foi a questão financeiro-fiscal. Suas ações objetivavam acabar com os mecanismos que os governos subnacionais tinham de repassar custos à União, pela criação de condições para que os estados conseguissem ajustar suas contas e pelo programa de privatização das empresas estaduais, assim buscavam também remodelar setores econômicos e obter recursos para quitar a dívida pública. Ademais, o seu segundo mandato, ainda focado na ótica econômica, concentrou-se na questão previdenciária, induzindo assim, a responsabilidade do bem-estar para os setores privados.

\section{Análise da Emenda Constitucional no 41/2003}

Promulgou-se a Emenda Constitucional n $41 / 2003$ com o objetivo de alterar as regras para a concessão de aposentadoria dos servidores públicos, que faz parte de uma série de medidas componentes da Reforma da Previdência. Esta emenda modifica e revoga artigos da CF/88 e da EC n ${ }^{\circ}$ 20/98.

A EC n 41/2003 alterou a idade mínima para aposentadoria dos servidores públicos de 48 anos de idade se mulher e 53 anos de idade se homem para 55 anos de idade se mulher e 60 anos de idade se homem. Criou o abono permanência equivalente a contribuição previdenciária para os servidores que tenham completado as exigências para aposentadoria voluntária e que opte por permanecer em atividade, até completar as exigências para a aposentadoria compulsória, 70 anos de idade. Bem como a integralidade e paridade sofreram alterações. Anteriormente o valor dos benefícios era o último salário da ativa, e com a emenda aqui discutida foi extinto essa regra, mantido apenas para quem tinha o direito adquirido.

Com essas alterações pode-se verificar que o abono permanência propicia ao servidor manter-se mais tempo no serviço para obter um maior benefício de aposentadoria. Dessa forma, o segurado fica condicionado ao mercado de trabalho por mais tempo, caso opte pelo abono. Assim, não há avanços nos aspectos da desmercadorização fazendo com que a enquadre em seu nível médio, ou seja, o indivíduo permanece dependente do mercado e o Estado mantém-se subsidiário, apresentando características do modelo welfare state conservador.

Outro aspecto analisado dessa EC no 41/03 é a integralidade e paridade dos servidores públicos que se manteve somente para aqueles que tinham direito adquirido na data da emenda. A retirada da integralidade reduz a possibilidade de o servidor conseguir o valor integral da sua aposentadoria. $\mathrm{E}$ a perda da paridade ocasiona a diminuição do valor aquisitivo das aposentadorias. Essas duas ações induzem características do modelo de WS liberal, que para este modelo a desmercadorização vai além quando comparada ao modelo de WS conservador, caminhando assim para uma dependência máxima do mercado, ou seja, uma desmercadorização mínima. 
Contudo, ao aumentar a idade para se aposentar, amplia também o tempo que o segurado irá contribuir, dessa forma a participação do Estado tende a se tornar menor, tangenciando o modelo Welfare State liberal. Uma questão importante de salientar é que ao realizar essa alteração, o segurado tende a trabalhar mais justamente no momento em que deveria estar gozando dos benefícios conquistados por ele.

Pode-se então concluir que essa emenda caminha do modelo conservador ao liberal. $\mathrm{O}$ fato de apresentar características similares ao modelo de WS liberal diz respeito também por verificar preocupações atuariais em detrimento das sociais. Assim sendo, apesar de apresentar nuances do modelo Welfare State conservador em alguns pontos, constata-se uma grande preocupação por parte do Estado com relação ao aspecto atuarial, ou seja, com os cofres previdenciários e preocupação mínima com o aspecto social. Distanciando majoritariamente do modelo social democrata que é caracterizado por uma desmercadorização máxima, emancipação do indivíduo do mercado e participação central do Estado.

\section{Análise da Lei ${ }^{0}$ 13.183/2015}

Essa lei trouxe importantes alterações na previdência social brasileira e é resultado da Medida Provisória $n^{\circ} 676 / 2015$, que mais tarde foi convertida na Lei $n^{\circ} 13.183 / 2015$. O novo sistema apresentado é uma alternativa ao fator previdenciário, sendo facultado ao contribuinte optar por uma das duas formas de cálculo. Trata também da alteração na Aposentadoria por Tempo de Contribuição - ATC com a implantação da Regra 85/95, como medida alternativa ao Fator Previdenciário.

Para a não aplicação do Fator Previdenciário e alcance do benefício da ATC integral, o beneficiário poderá optar pela Regra 85/95, que permite a exclusão do fator previdenciário do cálculo do valor das aposentadorias quando a pessoa atingir determinada pontuação com a somatória de idade e tempo de contribuição, sendo 85 pontos para as mulheres e 95 para os homens até dezembro de 2018. A regra atual é progressiva e sofrerá o acréscimo de um ponto a cada dois anos a partir de janeiro de 2019 até dezembro de 2026, quando a soma para as mulheres passará a ser de 90 pontos e para os homens de 100 pontos.

Constata-se que a regra 85/95 é uma regra transitória até alcançar a totalidade (90 para mulheres e 100 para homens) no ano de 2026. O objetivo da progressividade da regra é o de acompanhar o aumento da expectativa de vida dos brasileiros.

Dessa forma, a regra 85/95 no curto prazo tem características benéficas, pois concede oportunidade ao segurado da não utilização do fator previdenciário, podendo assim, se aposentar com o valor integral do seu salário. Contudo ela não traz benefícios universais por se tratar de um grupo específico que contribui a partir da sua ocupação econômica. Isto posto, já mostra características do modelo de Welfare State conservador/corporativista por abranger apenas um grupo seleto de segurados.

Já no longo prazo, essa regra 85/95 perde o caráter de vantajosa como foi caracterizada a priori, por necessitar de uma pontuação superior a pontuação inicial. Esse fato eleva a idade e o tempo de contribuição tornando a alternativa ao fator previdenciário não tão favorável, pois para a soma de 90/100 pontos o segurado já se encontrará com a idade avançada para requerer o seu benefício integral, retornando assim, as mesmas dificuldades enfrentadas com a aplicação do fator previdenciário. Diante deste cenário, observa-se que a participação do Estado é reduzida para manter o bem-estar do segurado fora do mercado de trabalho, sinalizando assim, uma desmercadorização mínima.

Além da regra 85/95 do Regime Geral contida nessa lei, há de se destacar também, outra medida que é a filiação obrigatória dos novos servidores públicos federais ao regime de Previdência Complementar (apenas para aqueles que tomarem posse no serviço público a partir de sua vigência). Como apresentado no artigo $4^{\circ} \S 2^{\circ}$ : 
Art. $4^{\circ}-\S 2^{\circ}$ Os servidores e os membros referidos no caput deste artigo com remuneração superior ao limite máximo estabelecido para os benefícios do Regime Geral de Previdência Social, que venham a ingressar no serviço público a partir do início da vigência do regime de previdência complementar de que trata esta Lei, serão automaticamente inscritos no respectivo plano de previdência complementar desde a data de entrada em exercício (Brasil, 2015).

Dessa forma, ao assumir o cargo, o servidor público federal já se encontra inscrito nesses regimes de Previdência Complementar, com as respectivas consequências contributivas em relação aos benefícios previdenciários, possuindo direito de requisitar seu desligamento posteriormente. Um ponto importante é que essa forma de inscrição involuntária nos regimes previdenciários complementares, afronta a $\mathrm{CF} / 88 \mathrm{em}$ seu art. 202 que caracteriza esses regimes como autônomos e facultativos. Essa filiação obrigatória também faz com que a lei tangencie o modelo Welfare State liberal, por subsidiar esquemas privados de previdência focando na lei do mercado.

\section{CONSIDERAÇÕES FINAIS}

A proposta do artigo foi de analisar as principais alterações legais acerca da Previdência Social após a Constituição Federal de 1988 com base nas tipologias de Welfare State Liberal, Conservador e Social-democrata, estabelecidas por Esping-Andersen. Para tanto discutiu-se no referencial teórico sobre o Histórico das Políticas Públicas de Previdência Social Brasileira e o Papel do Estado, assim como os Modelos de Estado de Bem-Estar Social.

Concluiu-se que os documentos legislativos analisados possuem características do modelo de Welfare State Conservador, por mais se aproximar do modelo brasileiro de previdência, devido ao princípio do mérito, baseado na posição ocupacional e de renda do indivíduo, constituindo a base da qual emergiu o sistema brasileiro de proteção social.

No entanto, na década de 90, com as crises econômicas, instituição e estabilização do plano real houve um estreitamento das políticas sociais, consequentes dos ajustes macroeconômicos o que tornou mais evidente as características do modelo WS liberal, distanciado ainda mais do modelo social-democrata que preconiza a participação central do Estado e a desmercadorização máxima.

Logo, as reformas brasileiras posteriores à instituição da Carta Magna possuem características dos modelos conservador e liberal. Não é de se estranhar, pois o próprio modelo de administração pública brasileiro pressupõe a coexistência de diferentes arquiteturas institucionais no aparelho Estatal.

No apanhado geral, observou-se que todas as alterações legais caminham para uma maior dependência do mercado e para uma menor atuação do Estado. Um ponto de grande relevância que cabe também destacar foi a vasta discussão a respeito da possibilidade de reforma da previdência (PEC 287/16) ocorrida a partir do ano de 2016 e muito discutida nos anos de 2017 e 2018. Na versão inicial da PEC 287/16, que caso houvesse se materializado por meio da reforma, traria fortes traços do modelo de WS liberal, devido principalmente à redução dos benefícios previdenciários e o foco nos aspectos econômicos e fiscais em detrimento aos aspectos sociais.

Observam-se que as mudanças na vida econômica e social que ocorreram no contexto das transformações do capitalismo, fazem com que os sistemas de proteção social vivenciem um dilema, pois é necessário continuar a beneficiar os mais vulneráveis, contudo o Estado percorre um período de dificuldade para atender a todas as demandas. Ocorre que a partir das análises das reformas, onde é enfatizada a busca da eficiência e resultados financeiros, a Previdência Social Brasileira é considerada a base de sustentação da economia de muitas famílias brasileiras de baixa renda. A análise corroborou a 
hipótese a qual afirma que as reformas da previdência ocorridas após a CF/88 baseadas no modelo de Welfare State de Esping-Andersen têm viés predominantemente econômico. Todavia, a previdência social brasileira mantém o conservadorismo em termos de agrupamentos, e não são integralmente liberais, por conter também o cunho social, ainda que em segundo plano, ele existe. Ou seja, predominam traços dos modelos de WS Conservador e Liberal.

Sendo assim, o artigo busca também contribuir para o entendimento das reformas previdenciárias ocorridas no Brasil e para os estudos acadêmicos no âmbito da previdência. Pesquisas que analisem as reformas desde antes da $\mathrm{CF} / 88$ e que façam uma análise comparativa em busca de compreender a realidade de cenários distintos podem ajudar a corroborar o estudo atual.

\section{REFERÊNCIAS}

BARDIN, L. Análise de Conteúdo. São Paulo: Edições 70, 2012.

BENEVIDES, C. do V. Um Estado de Bem-Estar Social no Brasil? 98 p. Dissertação (Mestrado). Departamento de Economia, Universidade Federal Fluminense, Niterói, 2011.

BRASIL. Constituição da República Federativa do Brasil de 1988. Título VIII, Capítulo II, artigos 194 a 203, Da Seguridade Social. Diário Oficial da União, Brasília, DF, 05 outubro 1988. 119p.

BRASIL. Emenda Constitucional no 20, de 15 de dezembro de 1998. Modifica o sistema de previdência social, estabelece normas de transição e dá outras providências. Disponível em:

<http://www.planalto.gov.br/ccivil_03/constituicao/emendas/emc/emc20.htm〉. Acesso em: 15 maio 2018.

BRASIL. Lei $\mathbf{n}^{\mathbf{0}}$ 8.540, de 22 de dezembro de 1992. Dispõe sobre a contribuição do empregador rural para a seguridade social e determina outras providências. Disponível em:

<http://www.planalto.gov.br/ccivil_03/Leis/L8540.htm>. Acesso em: 10 maio 2018.

BRASIL. Ministério da Previdência Social. A Previdência Social e a Revisão Constitucional. Brasília: CEPAL, 1994, $318 \mathrm{p}$.

BRIGGS, A. The Welfare State in historical perspective. In: BRIGGS, A.. The Welfare State Reader. Londres: Cambridge, 2006.

CAVALIERI, C. H. ; PAZELLO, E. T. Efeito distributivo das políticas sociais. In: BIDERMAN, C. ; ARVATE, P. (orgs.). Economia do setor público no Brasil. Rio de Janeiro, Elsevier, 2005. p. 339-364.

DRAIBE, S. O. Welfare State no Brasil. 1993. Disponível em:

$<$ https://sociologiajuridica.files.wordpress.com/2011/10/o-welfare-state-no-brasil-caracterc3adsticas-eperspectivas-sonia-draibe.pdf $>$. Consultado em 14 jun. 2018

ESPING-ANDERSEN, G.As três economias políticas do Welfare State. Revista Lua Nova. Rio de Janeiro, v.24, n.3, p. 55-68, 1991.

GUERREIRO, M. P. Análise dos Gastos Sociais Brasileiros na Perspectiva do Estado de Bem-Estar

Social: 1988 a 2008. Dissertação (Mestrado). Universidade Federal Fluminense, Rio de Janeiro, 2010.

GiAmbiagi, F., ALÉM, A. C. Finanças Públicas: teoria e prática. Rio de Janeiro, Elsevier. 2008.

GOMES, I. M. (2011), Previdência Social: Democracia, Participação e Efetividade. Belo Horizonte, Arraes Editores, 2011. 
GUIMARÃES, D. A. A.A importância das políticas públicas no Estado Democrático de Direito. MPMG Jurídico. São Paulo, v.4, n.1, 20 fev. 2006.

GURGEL, J. B. S. Evolução da Previdência Social. Brasília, Funprev Fundação Anasps, 2007.

HOBSBAWM, E. J. Rumo ao abismo econômico. In: HOBSBAWM, E. J. A era dos extremos: o breve século XX. São Paulo, Companhia das Letras, 1995.

HOBSBAWM, E. J. A era dos impérios: 1875 - 1914. São Paulo, Paz e Terra, 2016.

HOBSBAWM, E. J. Era dos Extremos: o breve século XX (1914-1991). São Paulo, Companhia das Letras, 2066.

HOVARTH, M. Previdência Social em face da Globalização. São Paulo, Quartier Latin, 2006.

IBRAHIM, F. Z. A Previdência Social no Estado Contemporâneo: Fundamentos, Financiamento e Regulação. Niterói, Impetus, 2011.

KERSTENETZKY, C. L. O Estado do bem-estar social na idade da razão: a reinvenção do Estado Social no mundo contemporâneo. Rio de Janeiro, Elsevier, 2012.

LAVILLE, C.; DIONNE, J. A construção do saber. Belo Horizonte, UFMG, 1999.

LOBATO, L. V. C. Políticas Sociais e modelos de bem-estar social: fragilidades do caso brasileiro. Saúde Debate. Rio de Janeiro, 40(esp.): p. 87 - 97, dez. 2016.

MENEZES, A. Direito Previdenciário. Petrópolis: Juspodivm, 2013.

SANTOS, D. F. C. dos. A Previdência Social no Brasil: 1923-2009 uma visão econômica. Porto Alegre: AGE, 2009.

SILVA, C. R. et al. O uso da análise de conteúdo como uma ferramenta para a pesquisa qualitativa: descrição e aplicação do método. Organizações Rurais Agroindustriais. Lavras, v.7, n.1, p. 70-81, 2005.

VIANA, M. L. T. W. A americanização (perversa) da seguridade social no Brasil: Estratégias de Bem-estar e políticas públicas. Rio de Janeiro, Revan, 1998.

WILENSKY, H. L. The Welfare State and equality. Berkeley: University of California Press, 1975. 